\section{Ocean Dynamics}

December 2009, Volume 59, Number 6, Pages 953-

968

http://dx.doi.org/10.1007/s10236-009-0221-6

(c) 2009 Springer. Part of Springer Science+Business

Media

The original publication is available at http://www.springerlink.com
Archimer, archive institutionnelle de l'Ifremer http://www.ifremer.fr/docelec/

\title{
Modelling for anchovy recruitment studies in the Gulf of Lions (Western Mediterranean Sea)
}

\author{
Amandine Nicolle ${ }^{1,{ }^{*}}$, Pierre Garreau ${ }^{1}$ and Bernard Liorzou ${ }^{2}$ \\ ${ }^{1}$ IFREMER, Dyneco/Physed, BP 70, 29280 Plouzané, France \\ 2 IFREMER, HMT/RH, BP 71, 34203 Sète, France \\ *: Corresponding author : A. Nicolle, Tel: +33298224330 , Fax: +33298224864 , email address : \\ amandine.nicolle@ifremer.fr
}

\begin{abstract}
:
Anchovy (Engraulis encrasicolus) is an important commercial species and one of the most abundant pelagic fish in the Gulf of Lions and the Catalan Sea. The factors influencing its recruitment are crucial to fisheries and ecological research. Among those factors transport of larvae by hydrodynamics (currents) is important because it determines whether the organisms can reach areas favourable to recruitment or are dispersed. Therefore, the first step in anchovy recruitment modelling is to simulate North-western Mediterranean Sea circulation. Several years (2001-2008) of hydrodynamics were simulated with the MARS-3D code. The resulting simulated currents and salinity are used by Lagrangian tool, Ichthyop, to transport anchovy eggs and larvae to the Western Mediterranean Sea. The aim of this study is to understand the main hydrodynamic processes that control anchovy transport and the effects of diel vertical migration on the transport and final distribution of anchovy.
\end{abstract}

Keywords: Anchovy - Mediterranean Sea - Numerical model - Gulf of Lions - Lagrangian transport Diel vertical migration 


\section{Introduction}

The Mediterranean Sea is a semi-enclosed basin considered as an oligotrophic zone (Estrada, 1996). The Gulf of Lions, located in the north-western part of the Mediterranean Sea, is one of the most productive areas of the Mediterranean Sea due to hydrographic features such as a wide shelf, strong vertical mixing in winter, coastal upwelling and river runoff (Lloret et al., 2000).

Anchovy, Engraulis encrasicolus, with sardine (Sardina pilchardus), is one of the most abundant pelagic clupeoid fish found in the Western Mediterranean Sea. Fishing pressure is heavier on anchovy due to higher prices for this species (Palomera, 1992). It is well-known that the variation in anchovy stock is not only due to fisheries but it also strongly relies on environmental conditions. As the main spawning areas in the North-Western Mediterranean are the Ebro and Rhone river mouths (Palomera, 1992), the anchovy egg production is expected to be linked to these rivers' runoff. Transportation and survival of eggs and larvae are also strongly dependant on currents, dispersion and stirring.

This study was carried out within the framework of SARDONE, a European project aiming at quantifying anchovy and sardine recruitment in the Mediterranean Sea. Three regions are considered in this project: the Adriatic Sea, the Aegean Sea and the Gulf of Lions, and the Catalan Sea, which is our region of interest. Anchovy was chosen as the first studied species due to its definite environmental and commercial interest and the need to complement knowledge regarding anchovy. Indeed, Palomera et al. (2007) observed a decrease in anchovy biomass in the Catalan Sea and the Gulf of Lions. They also noted overfishing due to the extension of the fishing season (Lleonart \& Maynou, 2003) and due to the fact that the minimum size of fish caught is smaller than that at first maturity (Palomera et al., 2003). We know that anchovy, like most clupeoids, spawns pelagic eggs, and its early life stages spent passively transported by ocean currents are particularly sensitive to environmental conditions (Lett et al., 2006).

Bakun (1996) proposed a fundamental triad, explaining how the physical environment may influence the recruitment of marine populations with an early pelagic life stage, based on 3 processes: enrichment, concentration and retention. The enrichment and concentration processes lead to areas where there is enough food for larvae, and the retention process enables the latter to stay in these favourable areas. This triad hypothesis was used in many papers to support recruitment interpretation (Lett et al., 2007; Hugget et al., 2003; Daskalov, 1999; Cubillos et al., 2002; Irigoien et al., 2007).

Various studies exist regarding the physical-biological coupled modelling of anchovy (e.g. Allain et al., 2007 (a) \& (b); Brochier et al., 2008; Boussouar et al., 2001; Mullon et al., 2003; Daskalov, 1999; North \& Houde, 2004). These papers present complex modelling methods (with several biological parameters such as time and space-dependent mortality and growth rate) in different areas: Bay of Biscay, Chesapeake Bay, Southern Benguela, and Black sea. In this part of the Mediterranean Sea, the basic lagrangian behaviour of eggs and larvae has not been yet investigated and the aim of the present study is providing the first step approach of the recruitment dealing with the contribution of the dynamics to transportation and dispersion. Biological accurate informations (conditions and area of spawning, eggs density, growth related to food, sensitivity to temperature stress, active swimming) are missing to build a realistic population dynamics modelling. Such information is expected as an issue of SARDONE experiment.

Therefore present study aims at better understanding the processes that control early-life anchovy transport and where 30-day-old anchovy larvae are concentrated. These preliminary results will allow us to understand whether we can explain the retention and concentration processes in the Gulf of Lions. 


\section{Gulf of Lions: observations}

\subsection{Geographical setting}

The Gulf of Lions (GL) is in the northern part of the Western Mediterranean Sea (fig. 1). It stretches over $250 \mathrm{~km}$ from east to west and $150 \mathrm{~km}$ from north to south. Circulation in its area is influenced by freshwater inputs, atmospheric forcing (wind and heat fluxes) and by the general circulation of the northern basin (Northern Current). Moreover, the bathymetry is complex, characterised by the presence of many canyons. The hydrological characteristics of the Gulf waters are influenced by the freshwater release of the Rhone River with salinity generally between 1 and 2 units lower than open sea waters (Millot, 1990). The mean flow of the Rhone River is $1,700 \mathrm{~m}^{3} . \mathrm{s}^{-1}$; it can reach $5,000 \mathrm{~m}^{3} \cdot \mathrm{s}^{-1}$ during the flood period, introducing a non-negligible buoyancy forcing on the Shelf. The wind regime is characterised by the predominance of two main winds: the Mistral (northerly wind) and the Tramontane (northwesterly wind). These winds generally blow for several days with a mean speed of 10-15 m. $\mathrm{s}^{-1}$ (Millot, 1990). Less frequent, sometimes strong, south-easterly gusts occur mainly at the end of summer and during autumn. Through interactions between the complex bathymetry and the surface wind curl, the Gulf of Lions dynamics is closely dependant of the succession of wind regimes.

\subsection{Anchovy behaviour}

PELMED campaigns, led by IFREMER, are acoustic surveys for pelagic fish stock estimation in the Gulf of Lions. Priority species observed in these campaigns are anchovy and sardine. These surveys have been providing data once a year, during summer, on anchovy behaviour since 1993.

The spawning area of anchovy is both the Gulf of Lions and the Catalan Sea. The spawning period lasts from May to September with maximum spawning intensity at the end of spring (Palomera, 1992), which corresponds to the period of maximum expansion of continental waters in the surface layer. The eggs and early larval stages are located in the surface layers of the water column, above the thermocline (Palomera, 1991), with 90\% of eggs found in the upper $15 \mathrm{~m}$ (Olivar et al., 2001). Consequently, the maximum abundance of anchovy eggs and larvae can be associated with areas of water of continental origin (Palomera \& Sabatés, 1990). Anchovy eggs are found in warm waters between 17 and $23^{\circ} \mathrm{C}$. This species is the only one that spawns in a wide salinity range including waters of continental origin. We can therefore consider that anchovy spawning takes place in all parts of the Gulf of Lions. The spawning habitat of anchovy is characterised by a main temperature peak $\left(17-19^{\circ} \mathrm{C}\right)$ and two salinity peaks (32-36\% and $37.5 \%$ ) (Palomera et al., 2007). Anchovy larvae present a passive behaviour until 7 days of age. After this period, they migrate vertically, by controlling its buoyancy, in the surface layer at night and in the area of the deep maximum of chlorophyll in the daytime (Olivar et al., 2001).

Estimates (PELMED campaign) for egg production (1,300 billion per day in 1994 and only 230 billion per day in 2007) stress the environmental application of this study.

\section{Modelling}

\subsection{Method}

On the basis of observations made on anchovy, we carried out numerical lagrangian transport experiments. A first type of experiment was achieved with passive transport (PT) at 15 metres depth. In the second type, we took into account diel vertical migration (DVM) for 7 - 
day-old larvae: they move down to 50 metres deep in the daytime and move up to the surface at night.

These two experiments were based on identical initial conditions: the homogeneous distribution of 100,000 eggs in the Gulf of Lions at $15 \mathrm{~m}$ depth. To follow the temporal evolution of the recruitment during the whole spawning period, we assume that anchovy spawning takes place each week from 15 May to 15 August in the Gulf. Recruitment of each cohort is evaluated after 30 days of transport because one month old anchovy larvae have real autonomous swimming movements. The Lagrangian tool is then no more suitable to describe the displacement of juveniles, without hazardous assumptions on the anchovy strategy to survive. To model anchovy transport, we first ran a hydrodynamic model (MARS3D) to obtain currents. We then used a lagrangian tool called ICHTHYOP to transport anchovy eggs and larvae in the Gulf during 30 days.

The results are presented in terms of retention and concentration. Retention represents the total number of eggs that stayed in the Gulf of Lions (i.e. in the spawning area) after 30 days of transport. Retention values are summed over the Gulf of Lions area and over depth. Concentration represents the number of eggs after 30 days per surface units. To simplify, the concentration is here the number of eggs or larvae per model grid cell, normalised by the initial eggs number in all area of modelling. Concentration values are summed over depth and are mapped. Anchovy eggs and larvae will often be named particles hereinafter.

\subsection{MARS Model}

Modelling is performed using MARS-3D (3D hydrodynamic Model for Applications at Regional Scale, IFREMER), a 3D primitive equation-free surface model applying the Boussinesq approximation and hydrostaticity (see a detailed description in Lazure \& Dumas, 2007). Spatial discretisation is achieved using a staggered "C" grid (Arakawa \& Lamb, 1977) and sigma vertical coordinates. The turbulent closure scheme used to compute the vertical turbulent diffusion coefficient is the TKE model proposed by Gaspar et al. (1990). In order to maintain horizontal mesoscale structures, horizontal viscosity is computed using a formulation proposed by Smagorinsky (1963), and dependent on local mesh dimensions and velocity gradients. For the purpose of this study, MARS-3D is used in its NW Mediterranean configuration (MENOR) with a horizontal resolution of $1.2 \mathrm{~km}$ and 30 sigma layers. The entire model domain covers the northern part of the Tyrrhenian Sea, the Ligurian Sea, the Gulf of Lions and the Catalan Sea to the north of the Balearic Islands, which is the zone of interest for this study far from open boundaries. Initial and boundary conditions were obtained from the MFS (Mediterranean Forecasting System) global model re-analysis available since the year 2001 (Pinardi et al., 2003). MFS-model data for temperature, salinity, current and sea surface elevation, which are provided every 24 hours with a $1 / 16^{\circ}(5-7 \mathrm{~km})$ resolution, are spatially and temporally interpolated into the MENOR grid. Atmospheric forcing is obtained every 3 hours from a high-resolution ( $3 \mathrm{~km}$ ) MM5 model embedded in the NCEP analysis for the years 2005, 2006 and 2007. Between 2001 and 2004, the results of the French MetOffice model ALADIN (10 km resolution) were alternatively used. MARS-3D for the NW Mediterranean is run in an operational mode since the beginning of 2005 , within the framework of the MOON project (http://www.moon-oceanforecasting.eu), producing 3-hourly simulations.

\subsection{Lagrangian model}

The ICHTHYOP lagrangian tool is used to simulate lagrangian transport of particles (anchovy eggs that develop into larvae) from the Gulf of Lions spawning grounds.

ICHTHYOP was developed by the IRD to study the way in which physical (e.g. ocean currents, temperature) and biological (e.g. growth, mortality, diel vertical migration) factors affect the dynamics of ichthyoplankton. It uses currents velocities, recorded every 3 hours, resulting from the hydrodynamic model, to transport ichthyoplankton. The advection scheme 
is based on the $4^{\text {th }}$ order Runge Kutta method. The release location of each individual is randomly chosen within the spawning area. A complete description of the tool is given in Lett et al. (2008).

ICHTHYOP takes into account many biological parameters such as egg buoyancy, larval growth, mortality... However, this study is focused on lagrangian transport and the only tested behaviour is diel vertical migration.

Therefore, the results of two experiments are compared. In the first, only passive transport at constant depth $(15 \mathrm{~m})$ is considered. In the second experiment, diel vertical migration is added: after 7 days, the larvae move down to 50 metres deep (corresponding to maximum chlorophyll) in the daytime (7 a.m.) and move up to the surface at night (7 p.m.).

Several parameters are fixed: (1) the release of 100,000 particles (anchovy eggs) per run is randomly distributed in the spawning areas at $15 \mathrm{~m}$ depth; (2) the spawning area (shown on fig.1) is defined as a rectangle with the longitude included between 3.0 and 6.0 deg., the latitude included between 42.0 and $43.6 \mathrm{deg}$. and bathymetry between 0 and 1,000 m; (3) spawning takes place each week from 15 May to 15 August; (4) the tracking period is 30 days.

\section{Results and discussion}

\subsection{Model validation}

The Menor configuration performed for this study is the one used in a pre-operational purpose and it has been already evaluated in the context of particular experiments and in situ measurements.

Validation of the MENOR configuration for the years 2005-2006 was carried out for the Gulf of Lions by comparing the main characteristics of the simulated shelf slope circulation with satellite observations (André et al., 2005) and with in-situ data (Drifting buoys and hydrological measurements) (André et al., 2008). Overall, the seasonal variability of general circulation (mainly the North Current (NC)), described by a large-scale cyclonic gyre over the North-Western Mediterranean basin, is accurately reproduced in the simulations (André et al., 2005). In winter, circulation is wide and intense due to winter convection. In summer, circulation weakens and splits into two parts, with a main gyre in the middle of the Northern Basin and a smaller one north of Corsica Island. Offshore from the Gulf of Lions, the velocity of the modelled NC ranges around $0.25 \mathrm{~m} / \mathrm{s}$ at the end of summer and $0.50 \mathrm{~m} / \mathrm{s}$ during winter. The water vein is about $30-50 \mathrm{~km}$ wide and the current flows at the top of the slope. In accordance with in-situ measurements (as well as with climatologic data), maximum velocity is reached at the subsurface and the vertical extension of the current is about $600 \mathrm{~m}$ deep (not shown). At mesoscales, the meanders and eddies of the NC are noticeable both in the modelled fields and sea surface temperature (SST) imagery, presenting similar length scales (André et al., 2005).

Using the same configuration, a particular attention has been paid to the wind induced current on the continental shelf of the Gulf of Lions for sediment dynamics evaluation (Dufois et al., 2008). The model is able to reproduce the known patterns of circulation generated by characteristic wind of this area (Mistral, Tramontane and South-Easterly winds).

Trajectories of buoys released in summer 2005, 2006 and 2008 over the slope front off Toulon have been favourably compared to modelling outputs. The North Current is a little bit to south at the eastern entrance of the Gulf of Lions but is correctly situated over the slope in the central and western part of the GL. It also exhibits realistic meanders and on-shore eddies (Rubio et al., 2009).

In this work, 8 years (2001-2008) of hydrodynamics were simulated with the MARS-3D model. The only one synoptic data available for a regional modelling assessment is the sea surface temperature. In this area of strong upwellings and frontal dynamics the sea surface 
temperature is not only an indicator of the vertical mixing but is also the consequence of the circulation.

The difference D between monthly mean forecasted SST and NAR satellite data (called innovation) is calculated by:

$\mathrm{D}=\mathrm{Y}-\mathrm{HXf}$, where $\mathrm{Y}$ represents NAR observations and $\mathrm{H}$ is the observation operator that projects model predictions Xf onto the observation grid. To avoid over-heating of the sea surface skin, during sunny and calm weather, we only take into account night outputs and data. Moreover data with a level confidence up to 3 are only used. In this case the observation operator is simply an affectation of the nearest coordinate temperature value.

Fig. 2 shows innovations from April 2002 to 2008 (the NAR satellite data of 2001 are not available). The differences between the observations and the model do not exceed 1 degree, except for 2007. Higher differences occur at the eastern and southern parts of the domain and, therefore, are located outside the studied area.

In the framework of SARDONE project two drifters were tracked by the Argos satellites system in the Gulf of Lions. Theses instruments were composed by a spherical buoys and a $10 \mathrm{~m}$ long holley-sock drogue centered $15 \mathrm{~m}$ below the surface. We have compared the trajectories of passive drifters computed using modelled currents with trajectory of real buoys released at the beginning of August 2007 in a potential spawning zone. Despite the natural dispersion, the trajectories of buoys are correctly reproduced by model (fig.3). The buoys remain 15 days in the Gulf of Lions before to be caught by the North Current and advected south-westwards. In both data and modelling the drifter are trapped by anticyclonic gyres on the Catalan shelf and the duration of the track is similar (1.5 months) from the Rhone mouth. Consequently, the model outputs can be considered sufficiently realistic to be used in lagrangian studies.

\subsection{The wind forced circulation}

It is well-known that circulation in the Gulf of Lions is strongly related to wind schemes and these wind structures have a short duration (Estournel et al., 2003; Petrenko et al., 2008). During our long term simulation, the wind driven circulations are on agreement with the results of above mentioned publications. When the Tramontane occurs in the western part and the Mistral in the eastern part of the Gulf of Lions (for instance from August, $4^{\text {th }}$ to August, $12^{\text {th }} 2005$; fig.4), typical circulation develops: near the west coast of the Gulf, a southward current appears. At the same time, a clockwise eddy forms in the northern part of the Gulf. Such eddies are able to capture particles (like eggs or passive larvae) during a more or less significant period of time. Moreover, according to the wind direction, the currents in the west part of the Gulf can be totally opposite: a spatially homogeneous northern wind induces a strong coastal current towards the south, whereas a spatially homogeneous north-westerly wind induces northwards alongshore jet. A particularly strong coastal jet appears along the coast when easterly wind occurs. These coastal currents can rapidly transport particles outside the Gulf of Lions or, on the contrary, prevent this transport. Due to this strong current, the Rhone plume stays near the coast and is less diffuse. This stronger presence of the Rhone plume in the GL can play an important role regarding the presence of nutrients for larvae. Despite the seasonality of wind regimes, circulation in the GL greatly varies according to the rapid alternation of the atmospheric situation. Therefore, we can suppose that wind is a main factor for early life behaviour of anchovy.

\subsection{Salinity and currents}

The spawning period of anchovy is linked to the decrease in salinity due to river runoff (Palomera, 1992; Palomera et al., 2007). Consequently, salinity and currents are key factor in the study of anchovy. The experimental design provides 13 larvae repartitions per year (weekly releases from May, 15th to August, $15^{\text {th }}$ ) during 8 years. For the sake of simplicity, attention is being paid firstly to the statistically most favourable period for anchovies spawn 
(mid May). Figure 5 shows (left column) the averaged salinity and currents at $15 \mathrm{~m}$ depth from 16 to 23 June (one month after spawn) according to wind direction (red arrows) during 8 years (2001-2008). Circulation in the Gulf of Lions varies according to different wind situations. This high variability of hydrodynamics is an important factor in larvae recruitment studies: if we consider that larvae are transported and depend on currents, we can note that, at the same spawning dates, larvae should have a very different history depending on the year.

The years 2005 (fig. 5 (e)) and 2006 (fig. 5 (f)) are periods of relatively higher salinity at $15 \mathrm{~m}$ depth. On the contrary, the years 2001 (fig.5 (a)), 2002 (fig.5 (b)), 2003 (fig.5 (c)), 2004 (fig.5 (d)), 2007 (fig.5 (g)) and 2008 (fig.5 (h)) are periods of lower salinity. For the other periods (not shown) from 15 May to 15 September, we observe the same annual trend for salinity. These results are not only a direct consequence of the Rhone mean flux (table 1) but are due to the mixing and transport of the Rhone plume that depend on wind circulation: according to wind direction and strength. The water column is more or less mixed and the residence time of the freshwater in the Gulf of Lions is also subject to variation.

Even though the years 2005 (fig.5 (e)) and 2006 (fig.5 (f)) are periods of high salinity, some areas of lower salinity comparable to other years are located along the coast for 2005 and in the western part of Gulf for 2006. Some buoyancy-driven currents are associated with lower salinity areas. For example, in 2005 (fig.5 (e)), a coastal current delimitates the lower salinity zone. In 2006, a lens of fresher water generates anticyclonic circulation that contributes to a possible retention area. These figures (fig.5) highlight the permanent presence of the Northern Current at the top of the slope. Does this strong current carry inner Gulf waters or is it a barrier between the Gulf of Lions and the open sea? This question is at the centre of many studies on the Gulf of Lions (e.g. Estournel et al., 2003; Durrieu de Madron et al., 2003; Petrenko et al., 2008; Lapouyade \& Durrieu de Madron, 2001).

\subsection{Experiment 1: passive transport (PT)}

The first experiment of lagrangian transport in the GL involves the passive transport of anchovy eggs during 30 days at a constant depth ( $15 \mathrm{~m}$ below the surface). The spawning area (fig.1) is the entire Gulf and spawning occurs each week from 15 May to 15 August.

Fig. 5 (central column) draws a parallel between the particles concentration maps, after 30 days of passive transport, and the $15 \mathrm{~m}$ averaged salinity and currents maps (left column) for 2001-2008. Generally, the maximum of particles concentration coincides with areas of low salinity except in 2006 (fig. 5f) where a lens of fresh water occurs in the northern part of the GL. The explanation of this result can be found in the formation of low-salinity water lenses. Lower salinity at 15 meters depth corresponds to older and vertical mixed waters. These lenses are formed from the Rhone plume freshwater and can capture and transport particulate and dissolved organic matter (Diaz et al., 2008). The Gulf of Lions is characterised by a general westward transport and no particles come back. Despite it strong mesoscale activity, the North Current is a barrier to particles and larvae can't cross over the shelf break. A weak counter-courant (eastward) has been described at the top of the slope (André et al., 2008) and is also present in the model. Nevertheless, particles cannot go durably to the east of the Gulf due to the presence of this strong westward current; it thus brings back particles to the west. The only efficient way for larvae to escape from the $G L$ is front of the Cap of Creus. During this transit towards the Catalan Sea, some eddy structures can slow down this transport. In 2002 (fig.5 (b)), some particles are caught in a gyre situated at north of Cap Creus and on the Catalan Shelf current. In 2003 (fig.5(c)), the cyclonic coastal currents located on the western coast of the Gulf correspond to higher particleconcentration zones. Particles are maintained in this gyre. In 2007 (fig.5 (g), eddies in the Gulf and higher particle-concentration areas can be superimposed. In 2008 (fig.5 (h)), a clockwise current is located south-west of the Gulf and coincides with the higher particleconcentration area. 
Obviously, particle distribution is controlled by currents: for example, in 2005 (fig.5 (e)), a salinity front with a strong current appears in the south of the domain and, on the concentration map (fig.5 central column), we see that some particles followed this current.

Outside the Gulf of Lions, eggs and larvae are advected on the Catalan shelf toward the Balearic Sea and the Balearic Front, following the global circulation pattern (fig 1). In 2002, 2004, 2006 and 2007 a secondary thermal front (situated between $41^{\circ} \mathrm{N}$ and $42^{\circ} \mathrm{N}$ ) pushes larvae in the central area south of the North Current. During summer this area is biologically poor and larvae are probably lost for recruitment.

\subsection{Experiment 2: diel vertical migration (DVM)}

The second experiment of lagrangian transport consists in adding DVM for 7-day-old larvae. The effects of DVM are shown in fig.5 (right column). The general patterns are identical to the above described experiment. On the one hand, the spatial distribution of particles appears less dense than in the first experiment. On the other hand, particles are more concentrated in filament structures. As a consequence, the results in term of global retention and residence time (discussed bellow) are not fundamentally different. Moreover, if we compare these results (fig.5 right column) with the salinity map (fig.5 left column), we observe that particles escape from the central part of the gyres by DVM but remain in lowersalinity areas. In the same way as in the first experiment, particles do not cross over the Northern Current. The Mistral (northerly wind) and the Tramontane (north-westerly wind) are not sufficient to expulse larvae out of the shelf when they are in surface layer. During the day the dynamics at $50 \mathrm{~m}$ depth keep larvae into the Gulf of Lions. All periods of spawning show the same observations. With DVM, when particles reach the surface, they can be captured by frontal convergence and transported by freshwater lenses and filaments. Vortices induce secondary currents that can lead to upwelling or downwelling in the vortex. In open ocean, nutrients are lifted upward, towards the surface by cyclonic eddies. In the Gulf of Lions, enriched fresher waters generate anticyclonic circulation and then downwelling. Therefore, anticyclones are convergence area and can thus concentrate surface particles (sea for instance Pasquero et al., 2007). The main effect of diel vertical migration is to concentrate particles in particular areas where salinity is lower.

\subsection{Number of particles that stay in the Gulf (retention)}

We focused our previous results on the spawning date of 22 May. We are now interested in the number of particles that stay in the GL at each spawning date during the 8 years.

Figure 6 shows the number of particles that stay in the Gulf of Lions (fig6 (a)) and those that go to the Catalan Sea (fig.6 (b)) after 30 days of lagrangian transport for the year 2005. Maximum particle retention in the GL obviously matches minimum particle abundance in the Catalan Sea. The same observations are made for the other years. Taking into account DVM (dotted curve in fig.6) has a limited effect on the number of particles that stay in the GL (between 25 and $45 \%$ for PT and $15-40 \%$ for DVM) but especially influences the number of particles that go to the southwestwards. Less particles reach the Catalan shelf with PT (continuous curve in fig.6). This proportion of particles reaching the Catalan Sea is comprised between 15 and 35\% for PT and between 20 and 50\% for DVM. There is a third category: particles that go away from the area of interest. This category represents around $40 \%$ for PT and DVM. In fig.5 (e), we see that 30-day larvae are concentrated in a front located outside the Catalan Shelf, with DVM. On the other hand, the temporal behaviour of particles is the same in both cases (fig.7). The number of particles that stay in the GL decrease regularly during the month.

The comparison between the temporal evolution of the number of particles that stay in the $\mathrm{GL}$ and the wind situation leads to a surprising result. The mean wind regime seems to have no real effect on particle retention (fig.8). The particles' minimum (35,000, i.e. $35 \%$ ) and maximum $(60,000$, i.e. $60 \%)$ are observed with the same mean wind conditions (for 
spwanning date at July, $3^{\text {rd }}$ and August, $14^{\text {th }}$ ). This result was not expected. Indeed, it is wellknown that currents of the GL are strongly related to wind (see $\S 4.2$ ). Therefore, we expected the exchange between the $G L$ and the Catalan Sea to be strongly related to wind circulation. On the contrary, there is no direct relation between the monthly averaged wind situation and the exchange between the Gulf of Lions and the Catalan Sea. The wind regime in the Gulf of Lions is characterized during spring and summer by a succession of different short time (i.e. few days) events. During one month, larvae are subject to many different weather conditions (Mistral, Tramontane, South-Easterlies, thermal breezes and calm weather) inducing opposite effects. The time scale of the meteorological forcing is too short as regard to size of the shelf. For instance a permanent south-easterly wind can efficiently flush the shelf (generating a strong coastal southward jet) but blows rarely for sufficient long time.

\subsection{Residence time}

Residence time of the Gulf of Lions shelf waters is between 1 and 2 months (Durrieu de Madron et al., 2003). This calculation of residence time $\mathrm{T}$ was based on salinity and water mass conservation.

In our experiments, we calculated t from the following formula (Lewis, 1998):

$N_{f}=N_{0} \exp \left(-\frac{t}{\tau}\right)$, where $\mathrm{N}_{\mathrm{f}}$ is the number of larvae that stay in the Gulf of Lions after one month and $\mathrm{N}_{0}$ is total number of spawned eggs. Residence time in the GL for 2005 (fig. 9) is somewhat lower with diel vertical migration. It is around 40 days for DVM and 45 days for passive transport. The other years show similar results. This residence time complies with the observations of buoys that can stay in the Gulf for more than a month.

Due to a relatively high residence time, one can conclude that anchovy larvae can stay sufficiently in the Gulf to be recruited. This would be beneficial to larvae because the Gulf waters are rich in nutrients coming from the Rhone River. Residence time of the GL tallies with the retention process of Bakun's triad. Particles can stay enough time in the GL, which is an area where nutrients are available to larvae.

\subsection{Effect of salinity}

Fig.10 highlights one main effect of diel vertical migration: particle distribution according to salinity is moved toward lower salinity in the case of DVM.

Therefore, the effect of diel vertical migration is the concentration of particles in areas of lower salinity. It seems to be a positive effect complying with observations. Fig. 10 also shows that there are often less particles that stay in the Gulf with DVM, but the fact that they are in lower salinity zones gives them more survival possibilities: we know that larvae must stay in areas with low salinity because this corresponds to zones with more freshwater, therefore with more nutrients (Diaz et al., 2008). If the larvae are captured and transported by freshwater lenses when they reach the water surface thanks to DVM, they definitely find enough food for their development.

If we consider the mean percentage per year of particles that stay in the Gulf of Lions, the results show that, for passive transport, in 2001, 2003, 2004, 2007 and 2008, 50\% of particles go to the Catalan Sea and 50\% stay in the Gulf of Lions. The ratio of years 2002, 2005 and 2006 is $60 \%$ out of the GL and $40 \%$ therein.

For DVM, the ratio is $80 \%$ out of the GL and $20 \%$ therein for 2002. For 2001, 2003, 2004, $2005,2006,2007$ and 2008 , it is $70 \%$ out of the GL and $30 \%$ therein.

Table 2 gives the mean percentage of particles for a different range of salinity between 36.8 and 38.4 PSU for both PT and DVM for each year. This percentage is calculated according to the number of particles that stay in the GL. These results highlight the fact that, for each 
year, the maximum of particles is moved toward a lower range of salinity for DVM. This is the most obvious in years 2001, 2006 and 2008.

Table 3 shows the mean percentage (over the 8 years) of particles for a different range of salinity between 36.8 and 38.2 PSU for both PT and DVM at each spawning date. The fact that the maximum of particles is moved toward a range of lower salinity for DVM is more clearly demonstrated at spawning dates between 5 and 19 June. Moreover, for both PT and DVM, we can see that the percentage of particles in range 38-38.2 PSU becomes higher in July and August (table 3 ). This result can be related to the Rhone runoff (table 1 ). The Rhone runoff decreases from June and its minimum is in July and August. Therefore, there is less freshwater input by the Rhone in summer.

\section{Summary / Conclusion}

This study is focused on lagrangian transport of anchovy eggs and larvae in the Gulf of Lions from 2001 to 2008. The results of the MARS-3D model show high hydrodynamics variability strongly related to wind in the Gulf of Lions. Lagrangian simulations show that, although circulation in the GL is strongly linked to the wind, particles retention in the Gulf of Lions appears to be independent of atmospheric forcing.

The main effect of diel vertical migration is the concentration of 30-day-old anchovy larvae in areas of lower salinity. Residence time is enough for larvae to stay in the Gulf during 40 days on average. This would mean that anchovy early stages would be in the appropriate conditions to survive according to Bakun's triad. The Gulf of Lions combines 3 fundamental processes: enrichment by land inputs of the Rhone and other smaller rivers, concentration in favourable areas by wind and buoyancy-driven circulation and overall retention on the shelf due to the northern current barrier. Therefore, the larvae are in areas where, in principle, there is enough food (a lower-salinity area often corresponds to more nutrients) and larvae can stay in these favourable areas (more than one month residence time).

According to Bakun, the Gulf of Lions is a potentially favourable area for anchovy recruitment.

The modelling method presented in this paper is a simple method with no real interactions between physical and biological processes. It would be necessary to take into account more parameters such as growth and mortality rates, presence of food and predators... in order to better understand the effects of natural phenomena on the presence of anchovy in the NorthWestern Mediterranean.

Furthermore, it would be interesting to take into account the fact that all eggs are not distributed in the same water layer and that vertical migration is not homogeneous. A realistic vertical distribution of eggs and larvae as well as a random walk parameterisation should reinforce these results. It would also be necessary to improve knowledge on larvae behaviour (diurnal migration, growth, mortality, buoyancy...) and knowledge on the effects of anthropogenic pressure (fishing activities).

\section{Acknowledgments}

This research was supported by the European project SARDONE.

We thank I. Palomera, A. Sabates and J. Salat (ICM, Barcelona) for their helpful discussions and contributions. The authors thank the two anonymous reviewers for their helpful and constructive comments that improved the manuscript. 


\section{References}

Allain G., Petitgas P., Lazure P. and Grellier P., 2007 (a). Biophysical modelling of larval drift, growth and survival for the prediction of anchovy (Engraulis encrasicolus) recruitment in the Bay of Biscay (NE Atlantic). Fisheries Oceanography, 16:6, 489-505.

Allain G., Petitgas P. and Lazure P., 2007 (b). The influence of environment and spawning distribution on the survival anchovy (Engraulis encrasicolus) larvae in the Bay of Biscay (NE Atlantic) investigated by biophysical simulations. Fisheries Oceanography, 16:6, 506-514.

André G., Garreau P, Garnier V. and Fraunié P., 2005. Modelled variability of the sea surface circulation in the North-Western Mediterranean Sea and in the Gulf of Lions. Ocean Dynamics, 55, 294-308.

André G., Garreau P. and Fraunié P., 2008. Mesoscale slope current variability in the Gulf of Lions. Interpretation of in-situ measurements using a three-dimensional model. Continental Shelf Research, Doi: 10.106/j.csr.2008.10.004.

Arakawa A. and Lamb V.R., 1977. Computational design of the basic dynamical processes of the UCLA general circulation model. In N. Heaps (Ed.), Methods in Computational Physics, 17, 173-265. Academic Press, New York.

Bakun A., 1996. Patterns in the ocean. Ocean processes and marine population dynamics. University of California Sea Grant, California, USA, in cooperation with Centro de Investigaciones Biologicas de Noroeste, La Paz, Baja California Sur, Mexico. 323 pp.

Boussouar A., Le Bihan S., Arino $O$ and Prouzet P., 2001. Mathematical model and numerical simulations of the migration and growth of Biscay Bay anchovy early larval stages. Oceanologica Acta, 24:5, 489-504.

Brochier T., Lett C., Tam J., Fréon P., Colas F. and Ayon P., 2008. An individual-based model study of anchovy early life history in the northern Humboldt Current system. Progress In Oceanography, 79:2-4, 313-325.

Cubillos L.A., Arcos D.F., 2002. Recruitment of common sardine (Strangomera bentincki) and anchovy (Engraulis ringens) off central-south Chile in the 1990s and the impact of the 1997-1998 El Niño. Aquatic Living Resources, 1, 87-94.

Daskalov G., 1999. Relating fish recruitment to stock biomass and physical environment in the black sea using generalized additive models. Fisheries Research, 41, 1-23.

Diaz F., Naudin J.J., Courties C., Rimmelin P. and Oriol L., 2008. Biogeochemical and ecological functioning of the low-salinity water lenses in the region of the Rhone river freshwater influence, NW Mediterranean Sea. Continental Shelf Research, 28, 1511-1526.

Dufois F., Garreau P., Le Hir P., Forget P., 2008. Wave- and current-induced bottom shear stress distribution in the Gulf of Lions. Continental Shelf Research, 28, 1920-1934.

Durrieu de Madron X., Denis L., Diaz F., Garcia N., Guieu C., Grenz C., Loÿe-Pilot M.D., Ludwig W., Moutin T., Raimbault P. and Ridame C., 2003. Nutrients and carbon budgets for the Gulf of Lions during the Moogli cruises. Oceanologica Acta, 26, 421-433.

Estournel C., Durrieu de Madron X., Marsaleix P., Auclair F., Julliand C., Vehil R., 2003. Observation and modeling of the winter coastal oceanic circulation in the Gulf of Lions under 
wind conditions influenced by the continental orography (FETCH experiment). Journal of Geophysical Research, 108:C3, 7-1 - 7-18.

Estrada M., 1996. Primary production in the northwestern Mediterranean. Scienta Marina, 60, 55-64.

Gaspar P., Grégoris Y., Lefevre JM, 1990. A simple eddy kinetic energy model for simulations of the oceanic vertical mixing: test at station Papa and long-term upper ocean study site. Journal of Geophysical Research, 95, 16179-16193.

Hugget J., Fréon P., Mullon C., Penven C., 2003. Modelling the transport success of anchovy Engraulis encrasicolus eggs and larvae in the southern Benguela: the effect of spatiotemporal spawning patterns. Marine Ecology Progress Series, 250, 247-262.

Lapouyade A. and Durrieu de Madron, 2001. Seasonal variability of the advective transport of particulate matte rand organic carbon in the Gulf of Lion (NW Mediterranean). Oceanologica Acta, 24:3, 295-312.

Lazure P., Dumas F., 2007. An external-internal mode coupling for a 3D hydrodynamical model for applications at regional scale (MARS). Advances in Water Resources, 31, 233250.

Lett C., Roy C., Levasseur A., Van Der Lingen C.D., Mullon C., 2006. Simulation and quantification of enrichment and retention processes in the southern Benguela upwelling ecosystem. Fisheries Oceanography, 15:5,363-372.

Lett C., Penven P., Ayon P., Fréon P., 2007. Enrichment, concentration and retention processes in relation to anchovy (Engraulis ringens) eggs and larvae distributions in the northern Humboldt upwelling ecosystem. Journal of Marine Systems, 64, 189-200.

Lett C., Verley P., Mullon C., Parada C., Brochier T., Penven P., Blanke B., 2008. A lagrangian tool for modelling ichthyoplankton dynamics. Environmental Modelling and Software, 23,1210-1214.

Lewis Roy, 1998. Dispersion in Estuaries and Coastal Waters. John Wiley and sons, 312 pp.

Lleonart J., Maynou F., 2003. Fish Stock assessments in the Mediterranean: State of the art. Scientia Marina, 67, 37-49.

Lloret J., Lleonart J., Solé I., 2000. Time series modelling of landings in Northwest Mediterranean Sea. ICES Journal of Marine Science, 57, 171-184.

Millot C., 1990. The Gulf of Lions' hydrodynamics. Continental Shelf Research, 10:9-11, 885894.

Mullon C., Fréon P., Parada C., Van Der Lingen C. and Huggett J., 2003. From particles to individuals: modelling the early stages of anchovy (Engraulis capensis/encrasicolus) in the southern Benguela. Fisheries Oceanography, 12:4-5, 396-406.

North E.W. and Houde E.D., 2004. Distribution and transport of bay anchovy (Anchoa mitchilli) eggs and larvae in Chesapeake Bay. Estuarine, Coastal and Shelf Science, 60, 409-429. 
Olivar MP, Salat J., Palomera I., 2001. Comparative study of spatial distribution patterns of the early stages of anchovy and pilchard in the NW Mediterranean Sea. Marine Ecology Progress Series, 217,111-120.

Palomera I., Sabatés A., 1990. Co-occurrence of Engraulis encrasicolus and Sardinella aurita eggs and larvae in the North-Western Mediterranean. Scientia Marina, 54, 61-67.

Palomera I., 1991. Vertical distribution of eggs and larvae of Engraulis encrasicolus in stratified waters of the western Mediterranean. Marine Biology, 111, 37-44.

Palomera I., 1992. Spawning of anchovy Engraulis encrasicolus, in the North-Western Mediterranean relative to hydrographic features in the region. Marine Ecology Progress Series, 79, 215-223.

Palomera I., Tejeiro B., Alemany F., 2003. Size at first maturity of the NW Mediterranean anchovy. SAC-GFCM, WG Small Pelagics, working document, 11. ftp://cucafera.icm.csic.es/pub/scsa/.

Palomera I., Olivar MP, Salat J., Sabatés A., Coll M., Garcia A., Morales-Nib B., 2007. Small pelagic fish in the NW Mediterranean Sea: An ecological review. Progress in Oceanography, 74, 377-396.

C. Pasquero, A. Bracco, A. Provenzale, J. Weiss, 2007. Particle motion in a sea of eddies. In Lagrangian Analysis and Prediction of Coastal and Ocean Dynamics, edited by A. Griffa, A. D. Kirwan, A. J. Mariano, T. Ozgokmen, and T. Rossby, Cambridge University Press.

Petrenko A., Dufau C., Estournel C., 2008. Barotropic eastward currents in the western Gulf of Lions, north-western Mediterranean Sea, during stratified conditions. Journal of Marine System, Doi:10.1016/j.jmarsys.2008.03.004.

Pinardi N., Allen I., Demirov E., De Mey P., Korres G., Lascaratos A., Le traon PY, Maillard C., Mazella G., Tziavos C., 2003. The Mediterranean ocean forecasting system: first phase of implementation (1998-2001). Annales Geophysicae, 21, 1-18.

Rubio A., Taillandier V. and Garreau P., 2009. Reconstruction of the Mediterranean northern current variability and associated cross-shelf transport in the Gulf of Lions from satellitetracked drifters and model outputs. Journal of Marine System, doi:10.1016/j.marsys.2009.01.011.

Smagorinsky J., 1963. General circulation experiments with the primitive equation. I. The basic experiment. Monthly Weather Review, 111, 99-165.

\section{Figures}

Fig. 1: Bathymetry map of study area. The release zone is represented by red rectangle.

Fig. 2: Sea surface temperature differences between model outputs and observations for April 2002-2008 (NAR satellite data of 2001 are not available).

Fig. 3: Trajectories of real buoys (blue and green lines) and passive drifters predicted by model (red points) for August-September 2007.

Fig. 4: Wind-induced currents when Mistral and Tramontane blow together. (a) Map of wind field between 4 and 12 August 2005. (b) Salinity and currents predicted by model. 
Fig. 5: Currents and salinity at $15 \mathrm{~m}$ depth averaged between 16 and 23 June with wind direction (red arrow) (left column). Particle concentration (logarithmic scale) after 30 days for passive transport (central column). Particle concentration after 30 days for diel vertical migration (right column). The spawning date is 22 May for (a) 2001, (b) 2002, (c) 2003, (d) 2004, (e) 2005, (f) 2006, (g) 2007 and (h) 2008.

Fig. 6: Number of particles that, after 30 days, (a) stay in the Gulf of Lions, (b) go to the Catalan Sea, after 30 days, for 2005.

Fig. 7: Temporal evolution of the number of particles that stay in the Gulf of Lions for (a) passive transport and (b) vertical migration, for 2006.

Fig. 8: Temporal evolution of the number of particles that stay in the Gulf of Lions according to wind conditions, for 2006.

Fig. 9: Residence time in the Gulf of Lions for 2005.

Fig. 10: Examples of distribution of particles that stay in the Gulf of Lions after 30 days according to salinity, at different spawning dates: (a) 22/05/2001, (b) 31/07/2002, (c) $15 / 05 / 2003$, (d) $14 / 08 / 2004$, (e) $05 / 06 / 2005$, (f) $05 / 06 / 2006$, (g) $10 / 07 / 2007$ and (h) 29/05/2008.

\section{Tables}

Table 1: mean flux of the Rhone River.

Table 2: mean percentage of particles per year for a different range of salinity.

Table 3: mean percentage of particles per spawning date for a different range of salinity. 
Bathy (m)

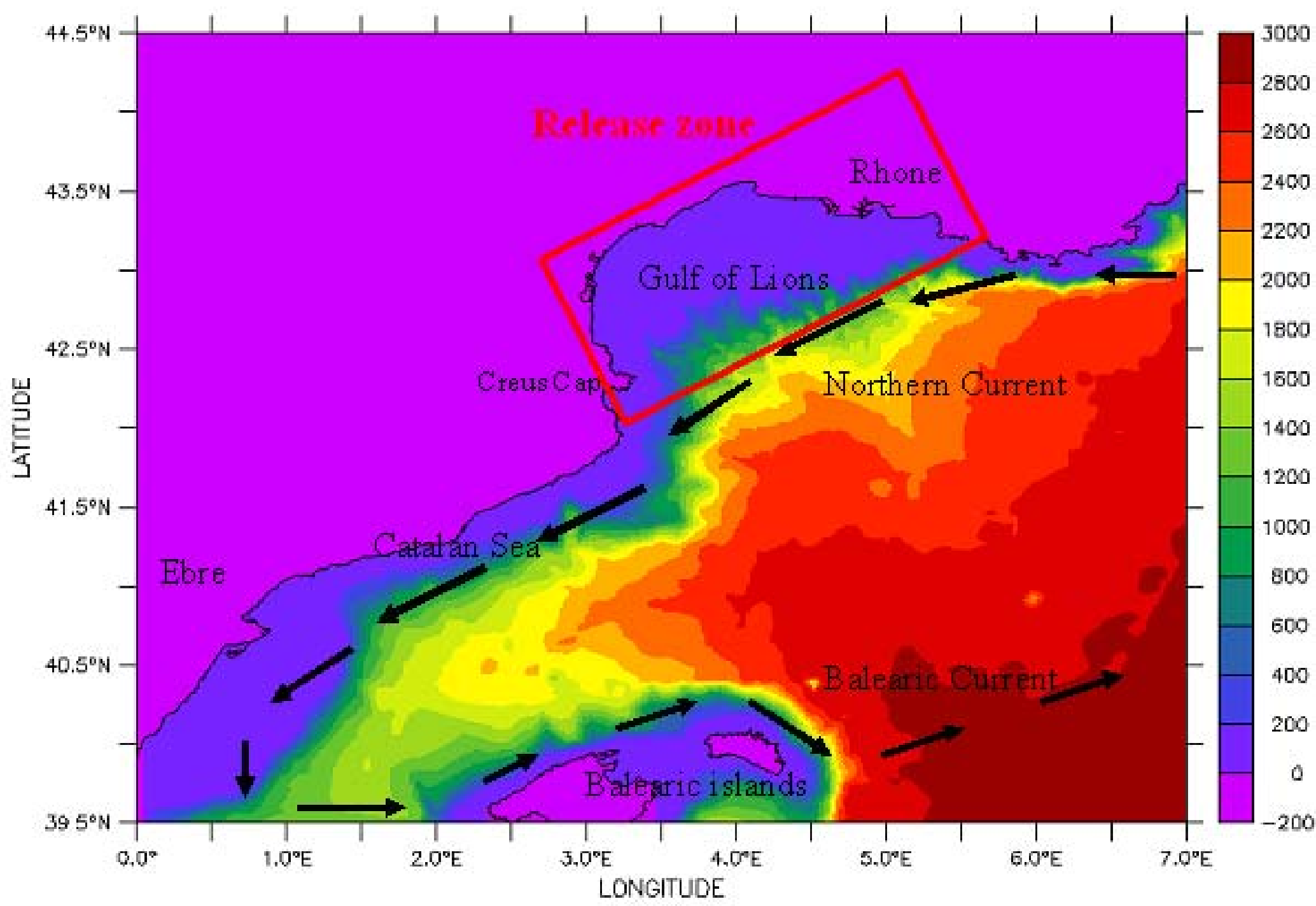

Fig. 1: Bathymetry map of study area. The release zone is represented by red rectangle. 


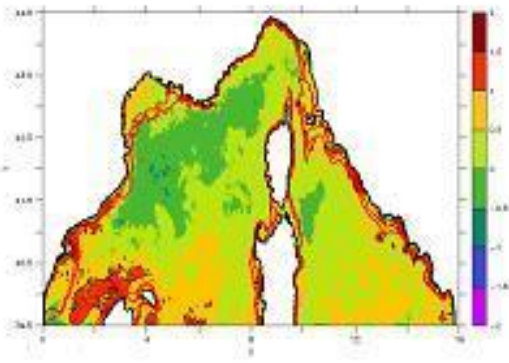

2002

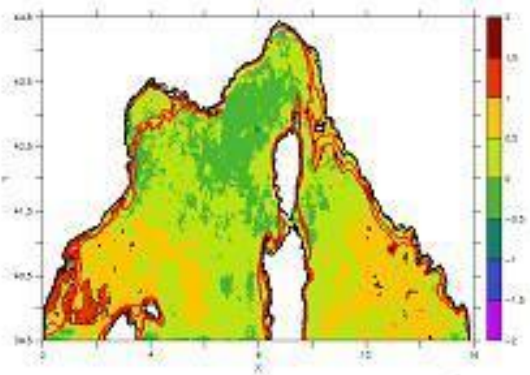

2005

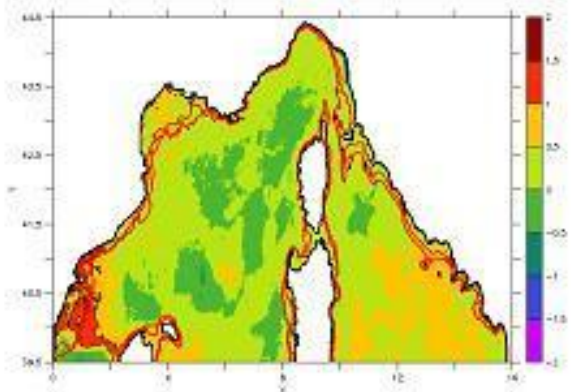

2008

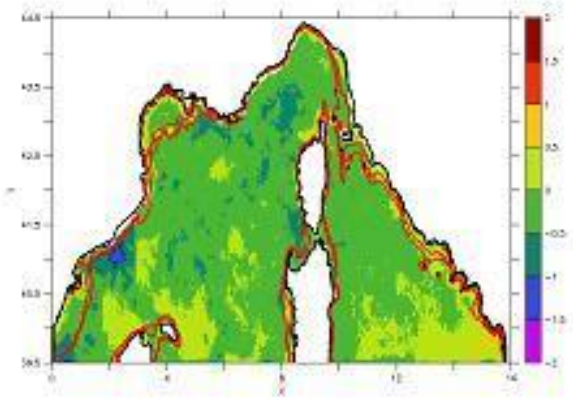

2003

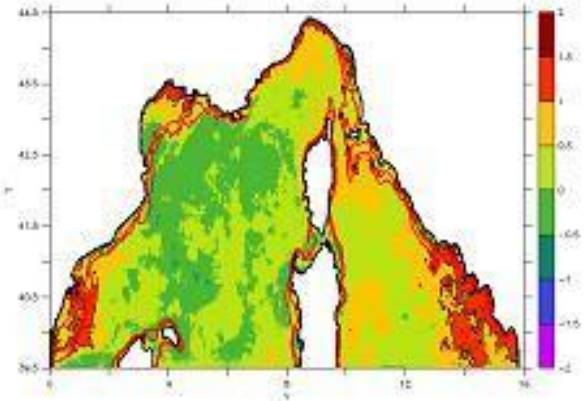

2006

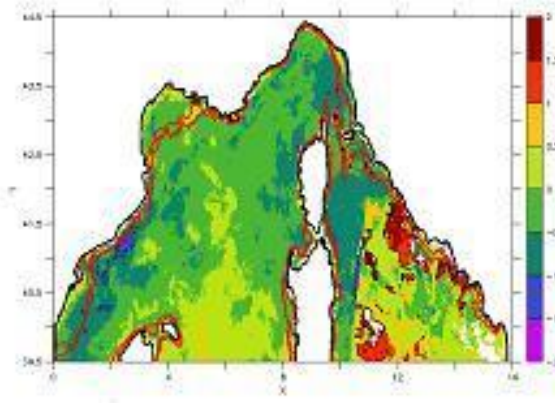

2004

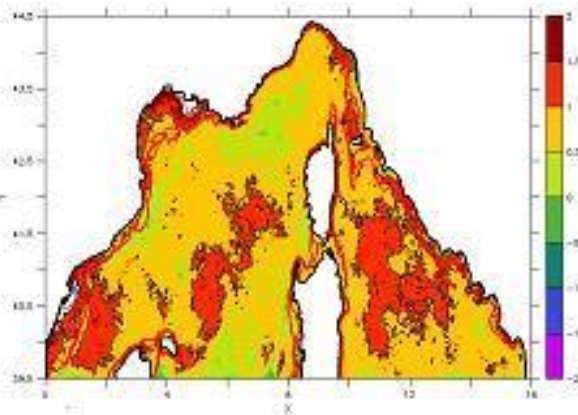

2007

Fig. 2: Sea surface temperature differences between model outputs and observations for April 2002-2008 (NAR satellite data of 2001 are not available). 


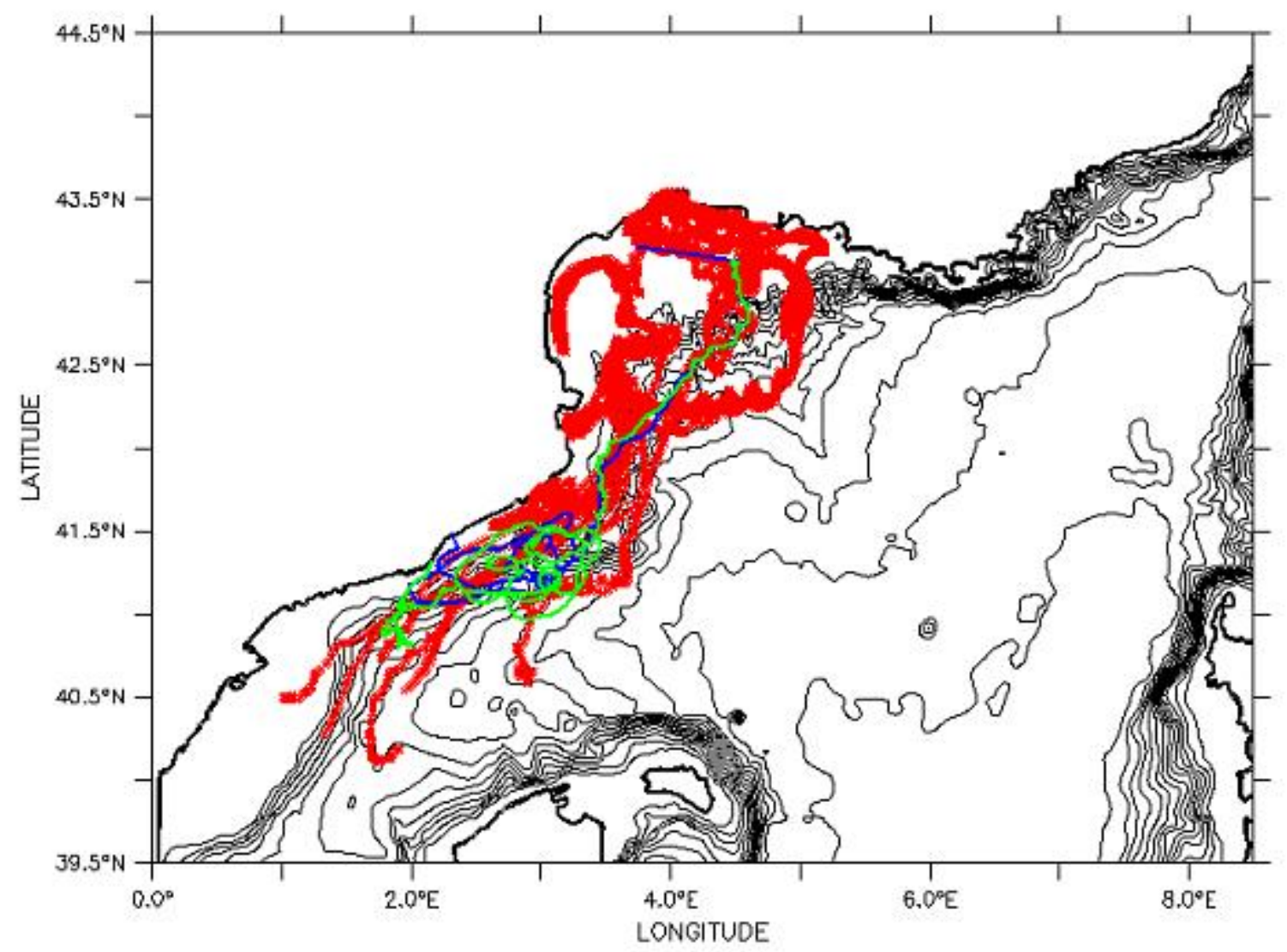

Fig. 3: Trajectories of real buoys (blue and green lines) and passive drifters predicted by model (red points) for August-September 2007. 


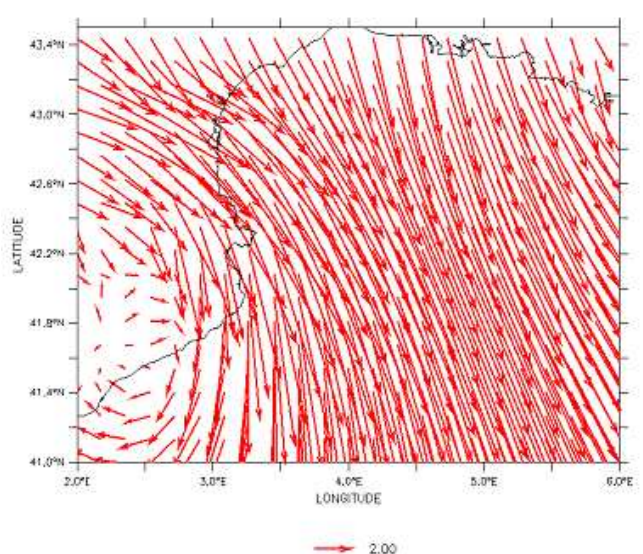

(a)

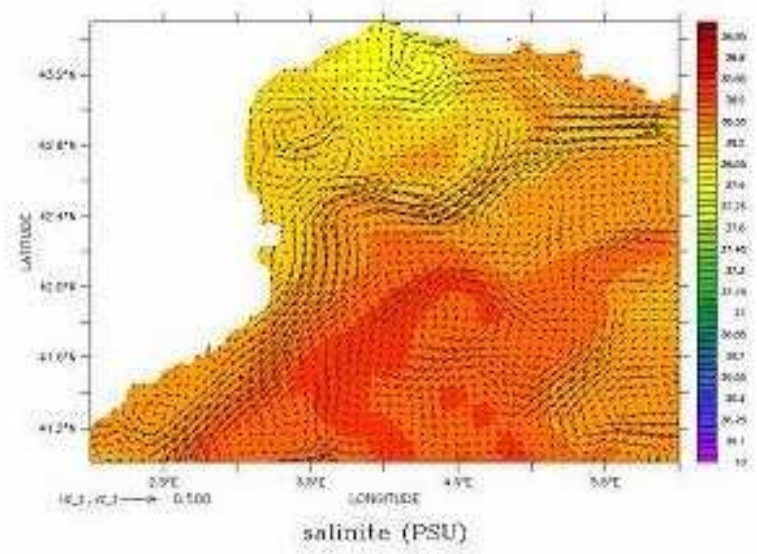

(b)

Fig. 4: Wind-induced currents when Mistral and Tramontane blow together. (a) Map of wind field between 4 and 12 August 2005. (b) Salinity and currents predicted by model. 

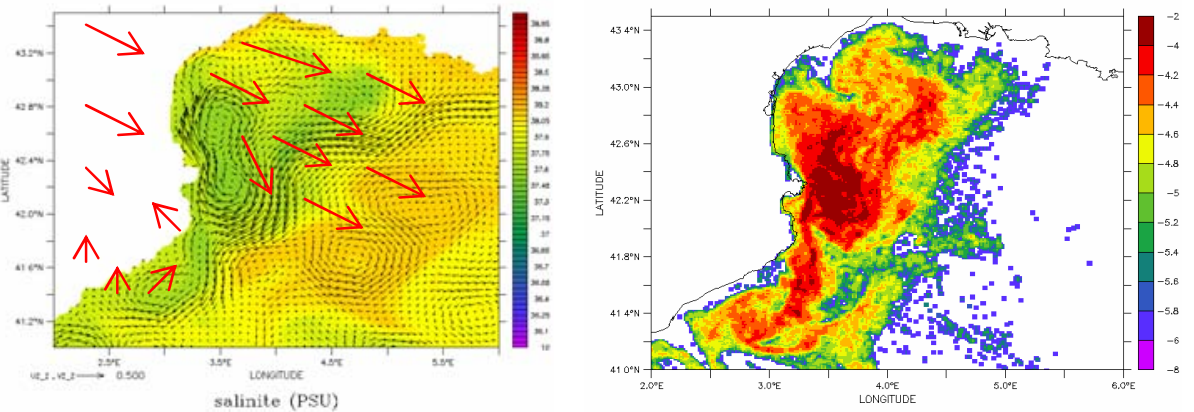

(a)
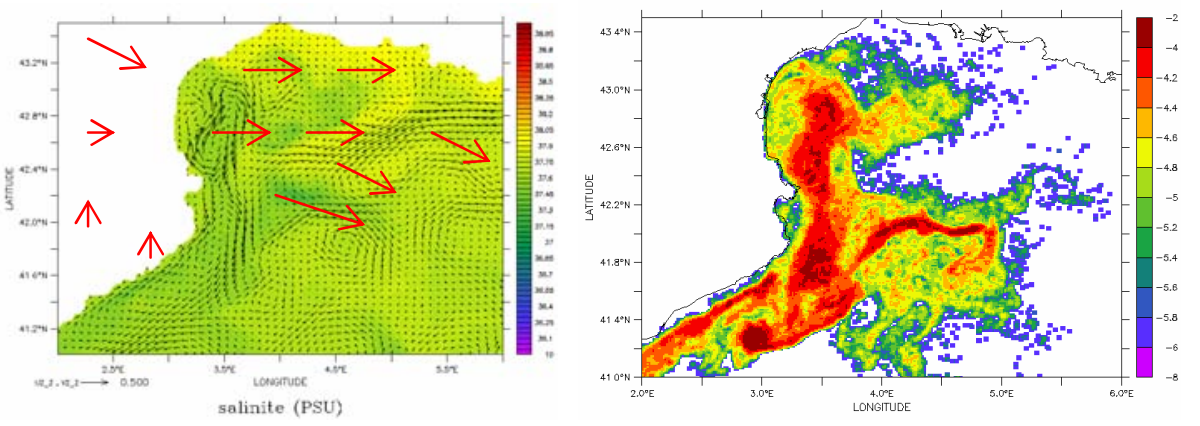

(b)
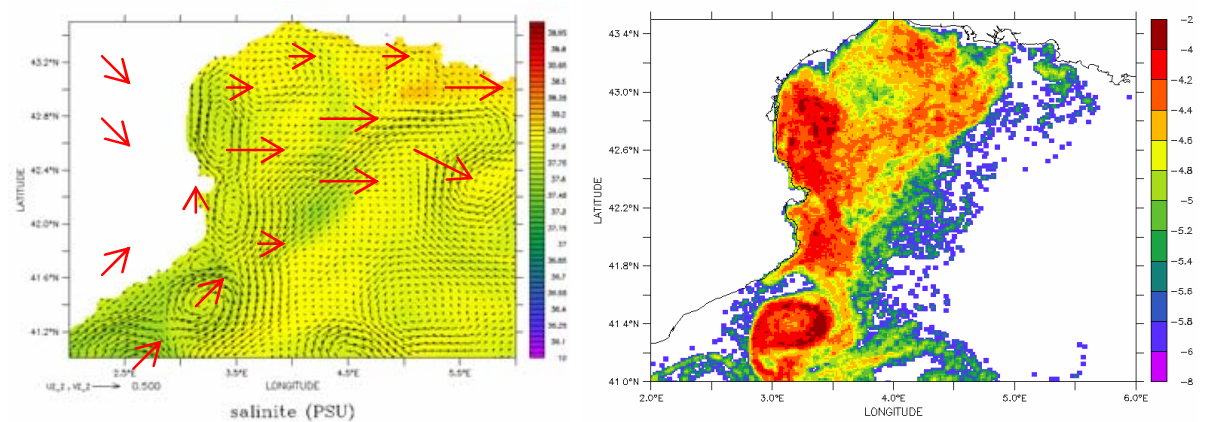

(c)
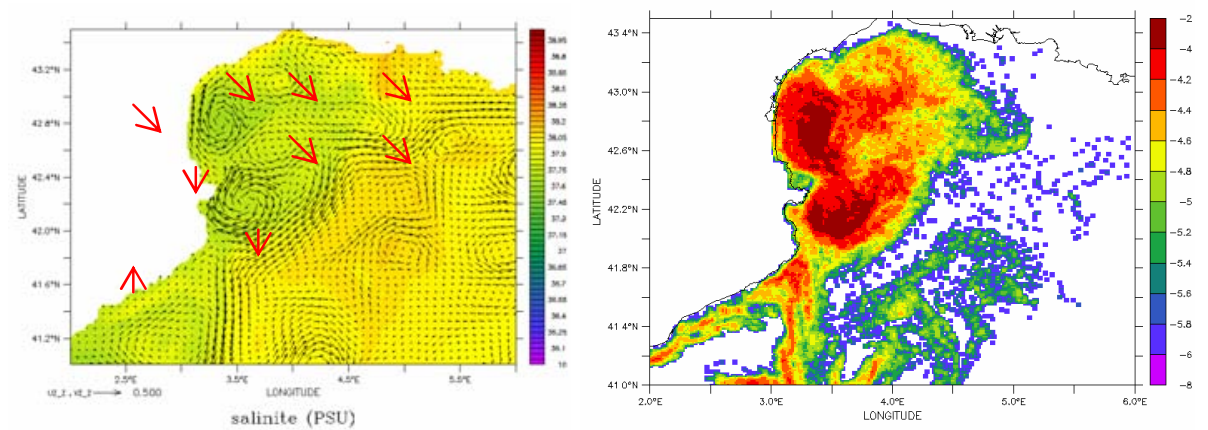

(d)
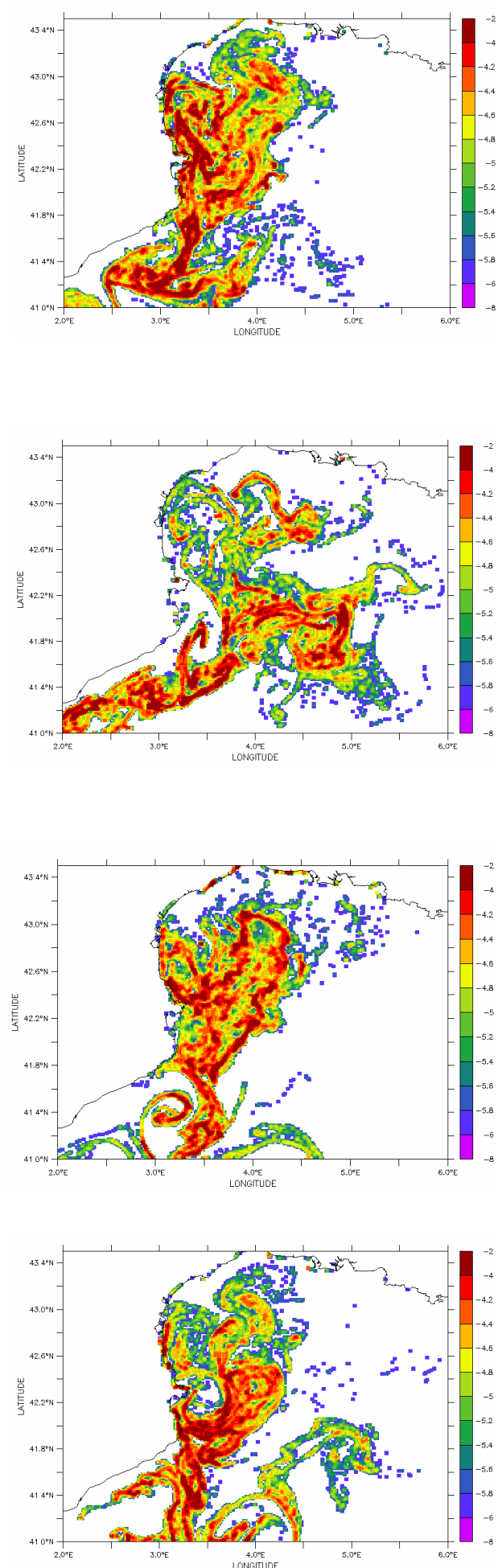

Fig. 5: Currents and salinity at $15 \mathrm{~m}$ depth averaged between 16 and 23 June with wind direction (red arrow) (left column). Particle concentration (logarithmic scale) after 30 days for passive transport (central column). Particle concentration after 30 days for diel vertical migration (right column). The spawning date is 22 May for (a) 2001, (b) 2002, (c) 2003, (d) 2004, (e) 2005, (f) 2006, (g) 2007 and (h) 2008. 

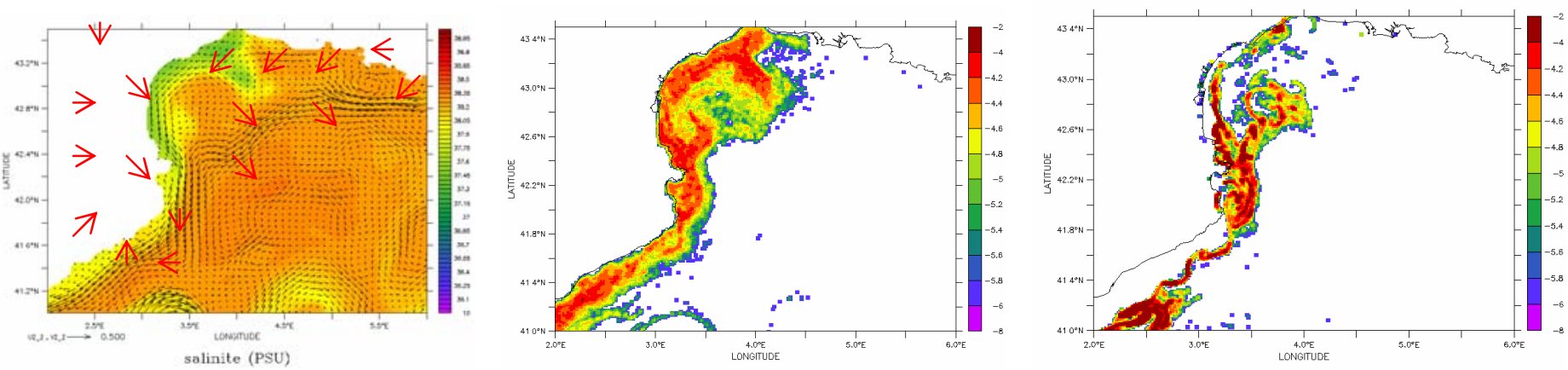

(e)
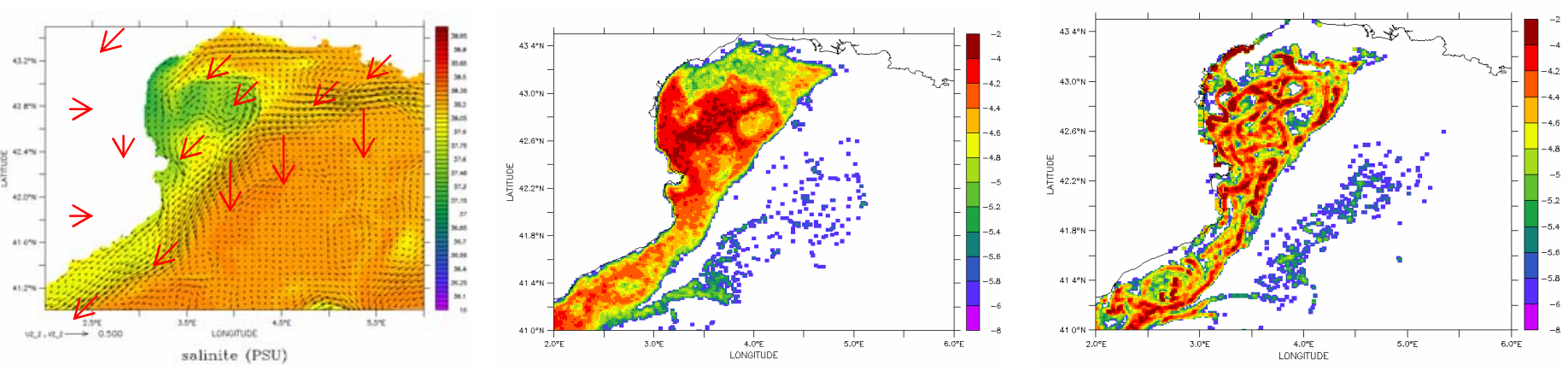

(f)
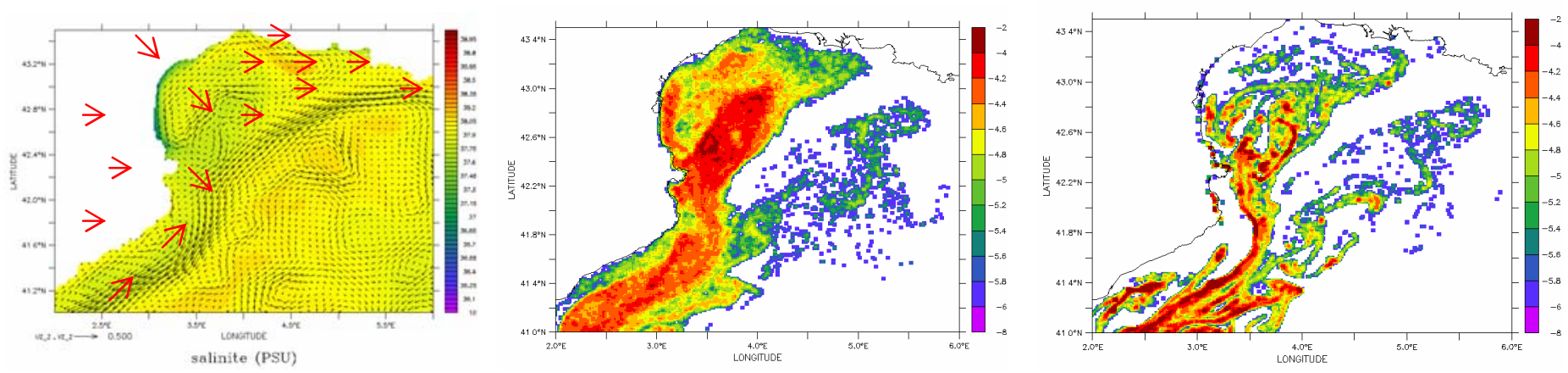

(g)

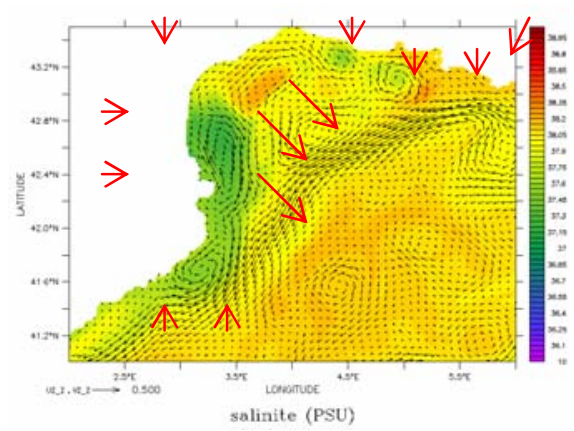

Fig.5 (continued)
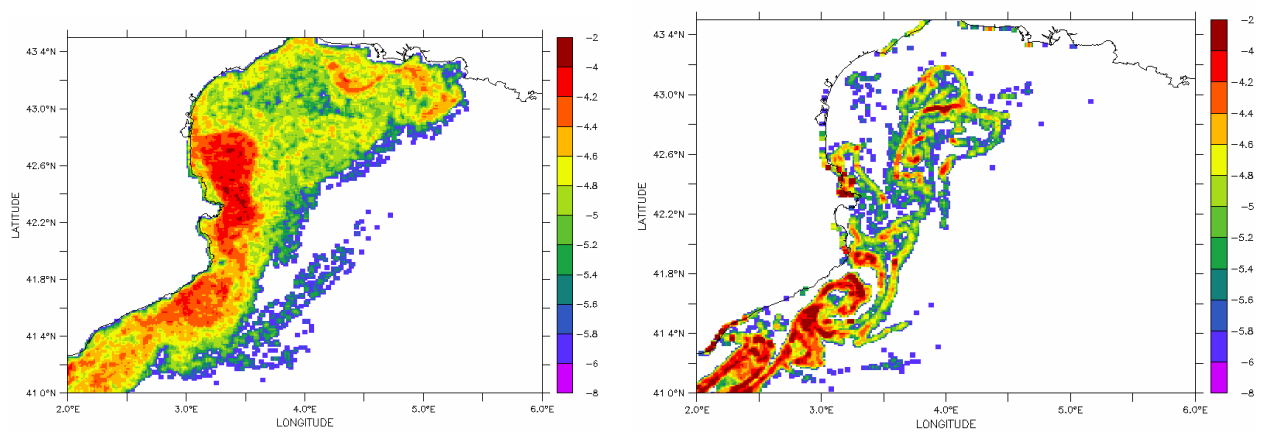

(h) 


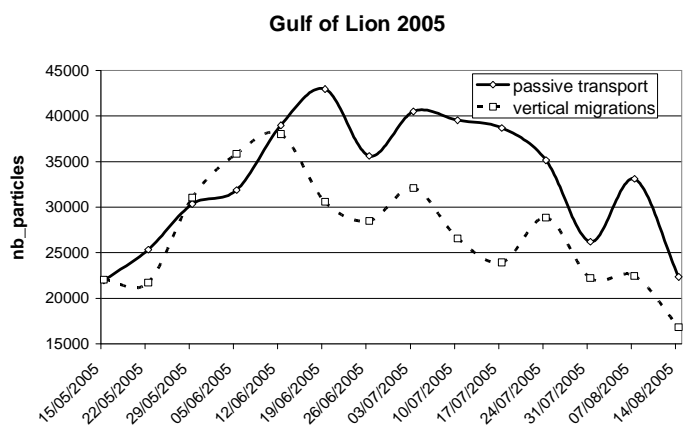

(a)

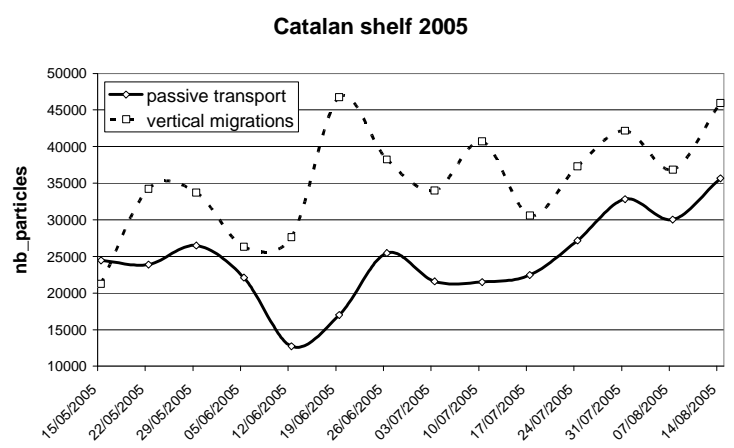

(b)

Fig. 6: Number of particles that, after 30 days, (a) stay in the Gulf of Lions, (b) go to the Catalan Sea, after 30 days, for 2005. 


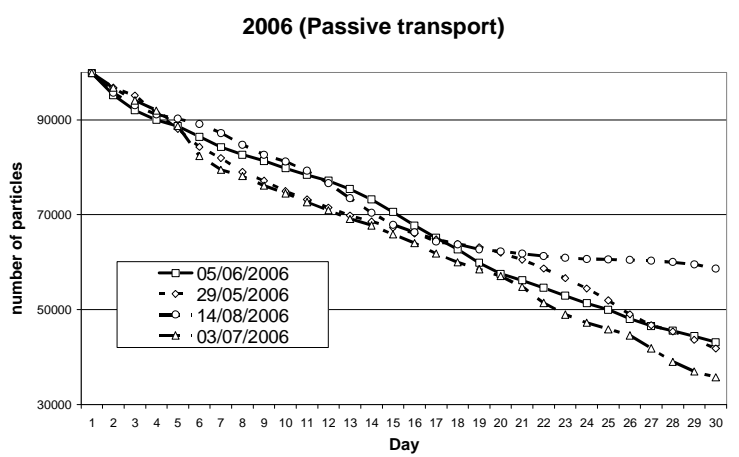

(a)

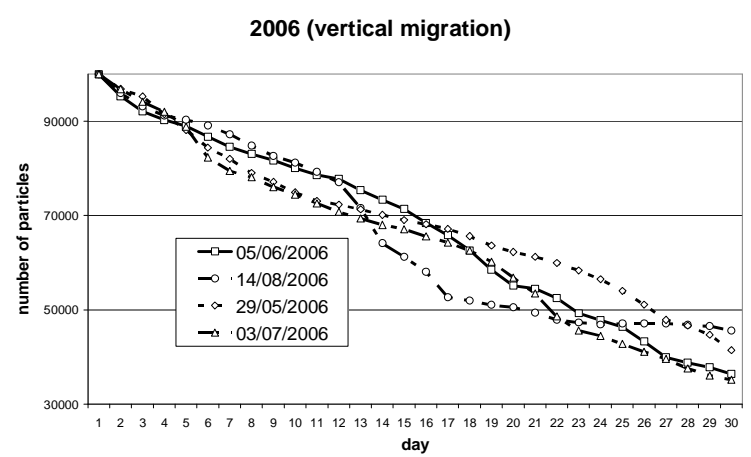

(b)

Fig.7: Temporal evolution of particles number that stay in Gulf of Lions for (a) passive transport and (b) vertical migrations for 2006 

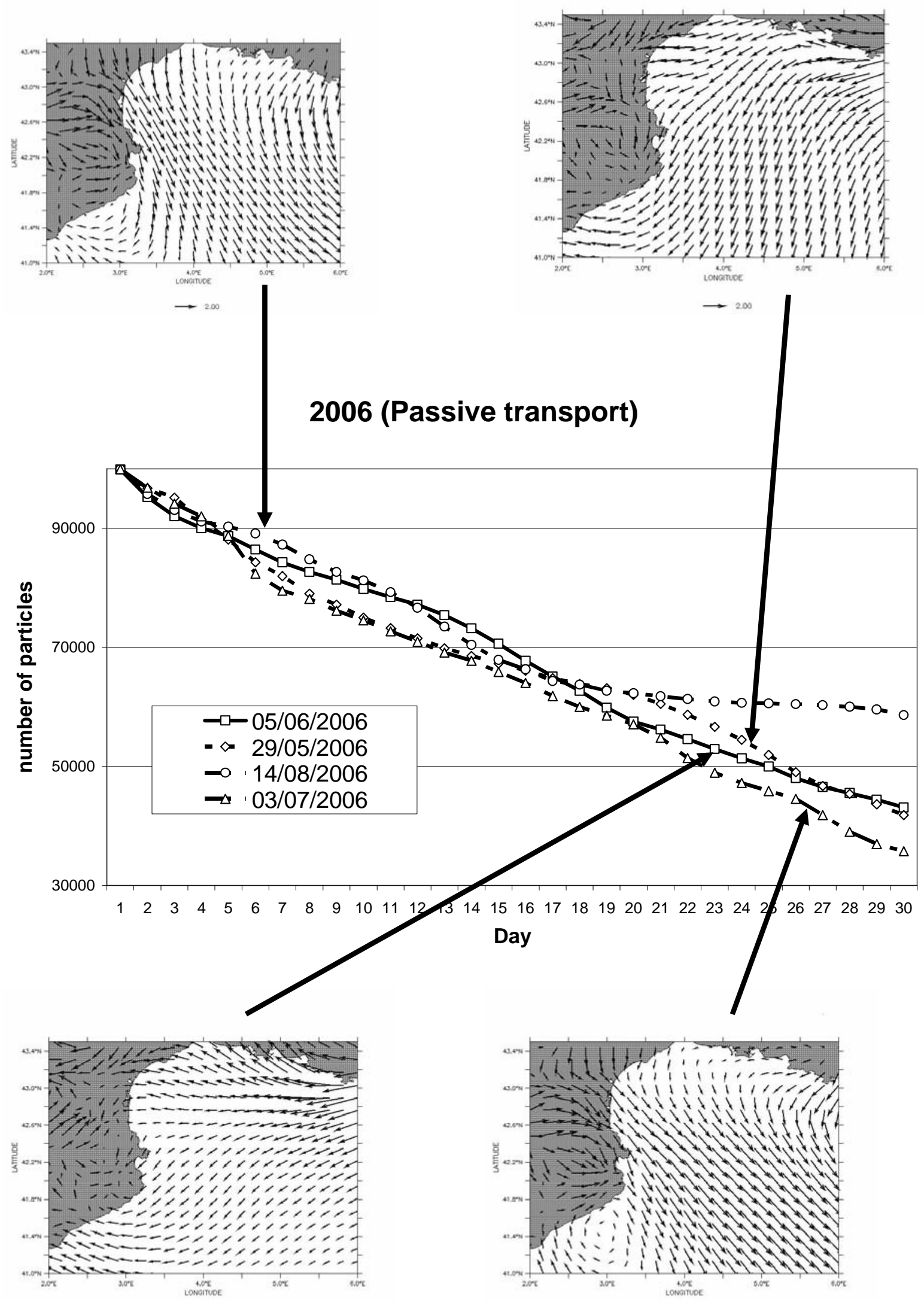

Fig. 8: Temporal evolution of particles number that stay in Gulf of Lions in relation with wind conditions for 2006. 


\section{Residence time in Gulf of Lion}

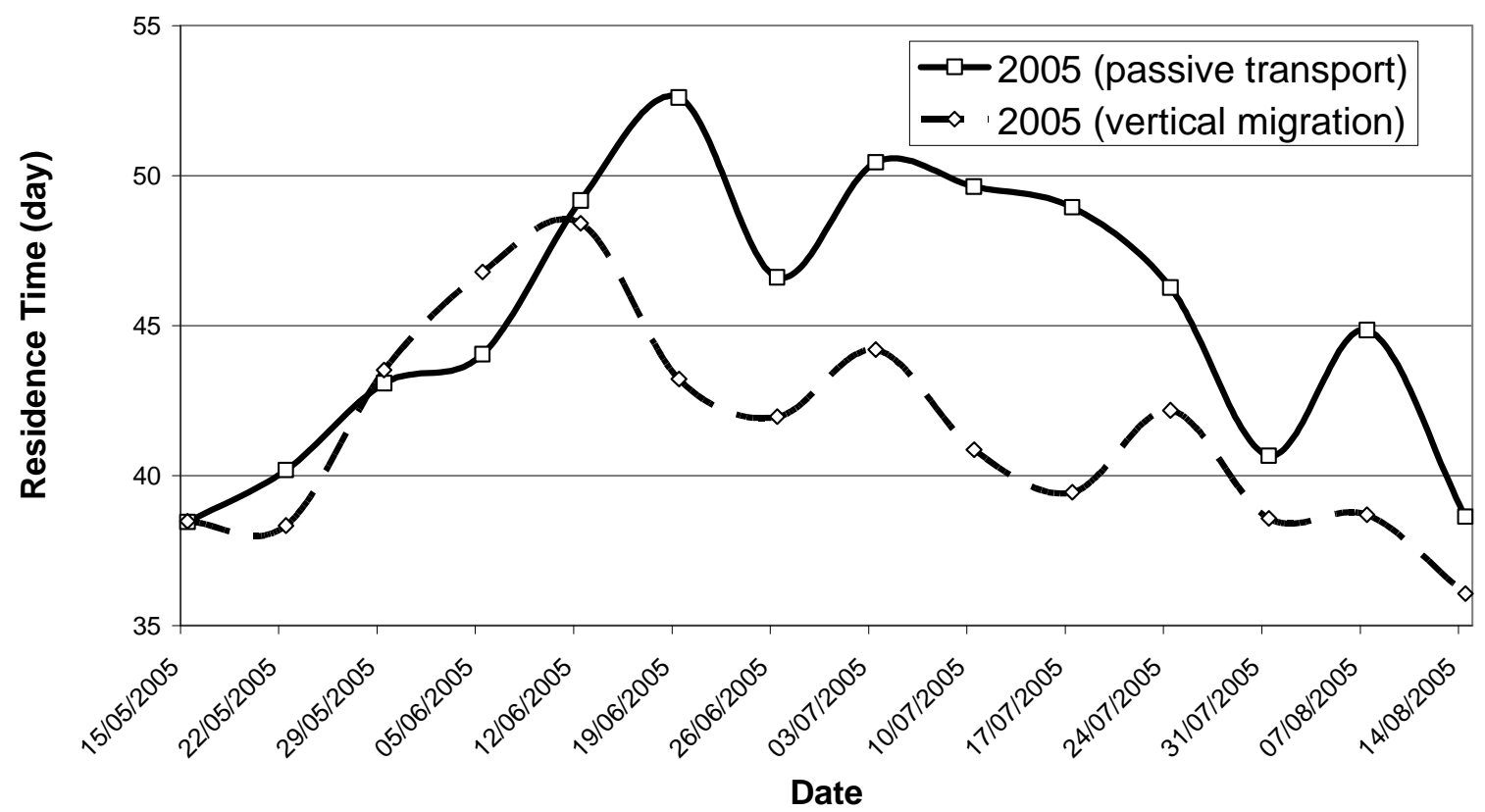

Fig.9: Residence time in Gulf of Lions for 2005 


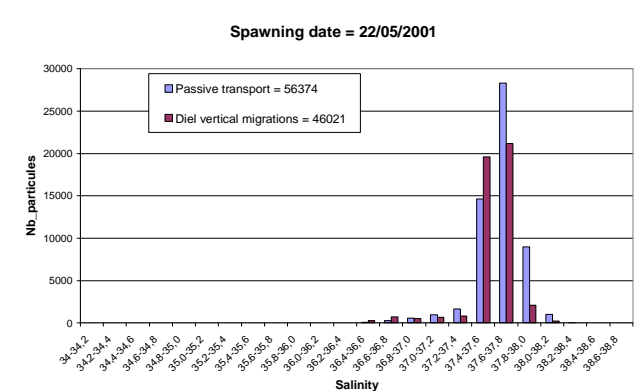

(a)

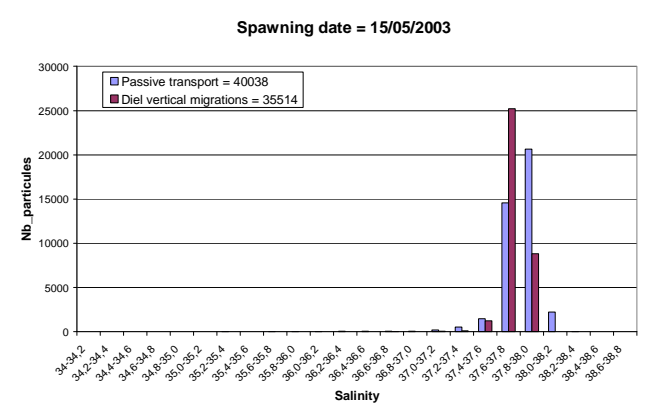

(c)

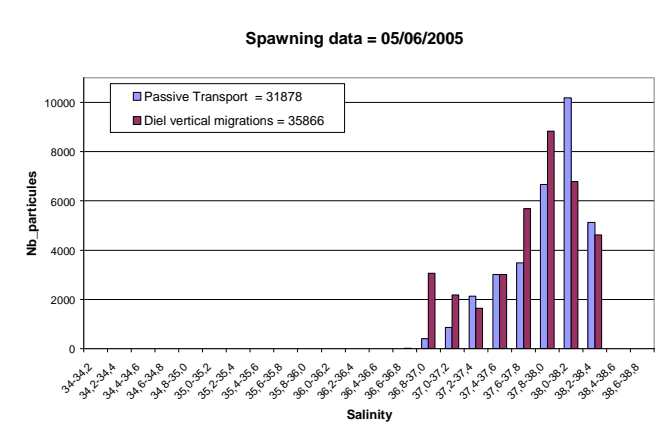

(e)

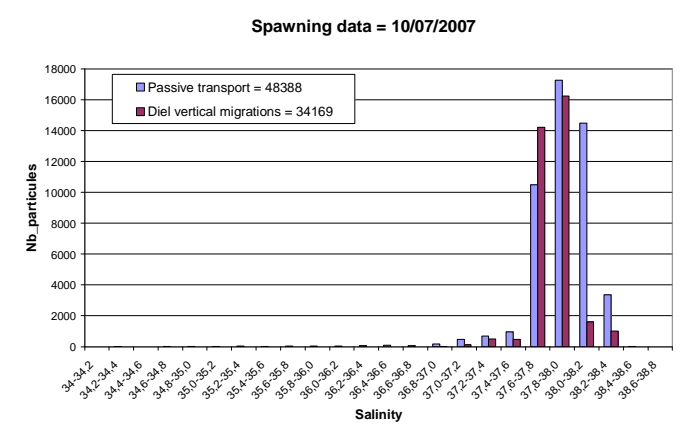

$(\mathrm{g})$

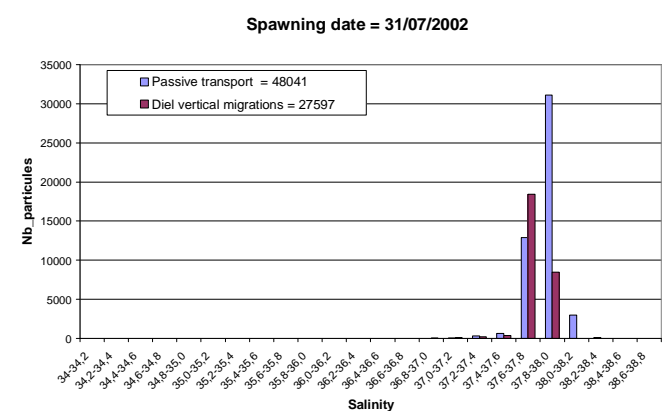

(b)

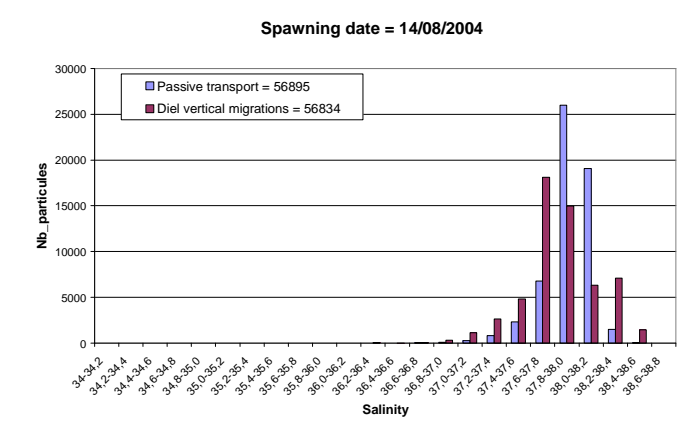

(d)

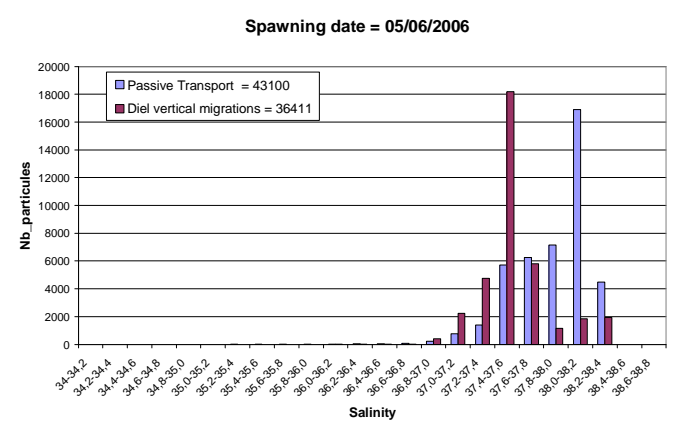

(f)

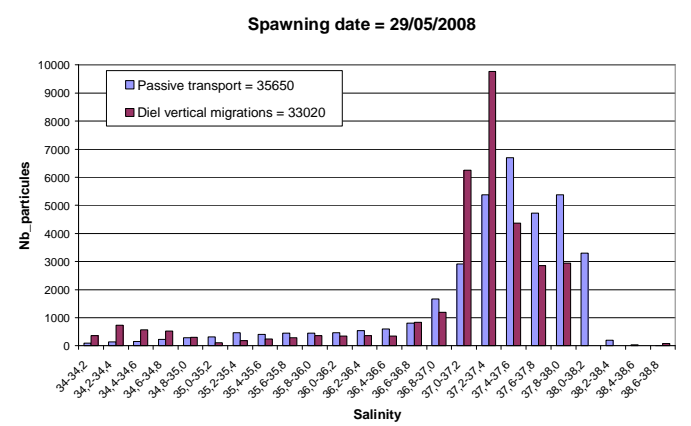

(h)

Fig. 10: Examples of distribution of particles that stay in the Gulf of Lions after 30 days according to salinity, at different spawning dates: (a) 22/05/2001, (b) 31/07/2002, (c) 15/05/2003, (d) 14/08/2004, (e) 05/06/2005, (f) $05 / 06 / 2006$, (g) $10 / 07 / 2007$ and (h) $29 / 05 / 2008$. 


\begin{tabular}{|c|c|c|c|c|c|c|c|c|c|}
\hline & total & 2001 & 2002 & 2003 & 2004 & 2005 & 2006 & 2007 & 2008 \\
\hline april & 1756,84 & 3027,30 & 841,43 & 1078,27 & 1209,53 & 2531,33 & 2619,86 & 990,14 & 2383,75 \\
\hline may & 1587,00 & 2724,87 & 1628,06 & 1078,00 & 1183,71 & 1414,14 & 1723,28 & 1356,92 & 1869,20 \\
\hline june & 1321,34 & 1943,60 & 1307,20 & 961,93 & 1091,97 & 939,39 & 1052,66 & 1952,62 & 2650,00 \\
\hline july & 1034,32 & 1531,48 & 981,39 & 704,32 & 750,39 & 732,10 & 845,39 & 1695,19 & 1286,87 \\
\hline august & 1005,75 & 1038,29 & 1021,00 & 764,03 & 1138,19 & 706,65 & 996,54 & 1375,53 & 1029,96 \\
\hline september & 955,50 & 1211,13 & 1237,07 & 739,60 & 787,30 & 872,54 & 972,84 & 868,04 & 1869,42 \\
\hline
\end{tabular}

Table1: mean flux of Rhone river

\begin{tabular}{|c|c|c|c|c|c|c|c|c|c|c|c|c|c|c|c|c|}
\hline & \multicolumn{2}{|c|}{2001} & \multicolumn{2}{|c|}{2002} & \multicolumn{2}{|c|}{2003} & \multicolumn{2}{|c|}{2004} & \multicolumn{2}{|c|}{2005} & \multicolumn{2}{|c|}{2006} & & \multirow{2}{*}{\multicolumn{2}{|c|}{2008}} \\
\hline & PT & DVM & PT & DVM & PT & DVM & PT & DVM & PT & DVM & PT & DVM & PT & DVM & PT & \\
\hline $36,8-37$ & 0,47 & 0,66 & 0,16 & 1,25 & 0,17 & 0,26 & 0,13 & 0,36 & 0,77 & 1,77 & 0,35 & 1,00 & 0,81 & 1,01 & 1,88 & 1,30 \\
\hline $37-37,2$ & 0,80 & 1,22 & 0.45 & 2,82 & 0,41 & 0,74 & 0,30 & 0,73 & 1,38 & 1,75 & 1,51 & 4,43 & 1,35 & 1,56 & 3,59 & 4,47 \\
\hline \begin{tabular}{|l|l|l|l|l|l|l|}
$37,2-37,4$ \\
\end{tabular} & 2,26 & 4,29 & 1,42 & 7,32 & 1,03 & 1,63 & 0,62 & 1,54 & 2,69 & 1,99 & 5,98 & 9,06 & 3,09 & 2,93 & $\begin{array}{l}0,05 \\
7,85\end{array}$ & $\begin{array}{l}4,41 \\
11,07\end{array}$ \\
\hline $37,4-37,6$ & 7,57 & 14,46 & 10,61 & 20,80 & 2,57 & 3,67 & 2,33 & 4,67 & 3,87 & 4,68 & 9,18 & 15,86 & 7,13 & 7,84 & 13,34 & 18,88 \\
\hline $\mid \frac{10,4-3,0}{37,6-37,8}$ & $\frac{1,31}{22,46}$ & $\begin{array}{l}11,40 \\
30,77\end{array}$ & $\frac{0,01}{42,17}$ & $\frac{20,00}{48,58}$ & $\frac{L, 31}{13,31}$ & $\frac{3,01}{20,62}$ & $\frac{L, 30}{20,83}$ & $\begin{array}{l}4,01 \\
28,23\end{array}$ & $\begin{array}{l}3,01 \\
5,65\end{array}$ & $\begin{array}{l}, 00 \\
9,07\end{array}$ & $\frac{9,10}{11,84}$ & $\frac{11,00}{12,56}$ & $\frac{1,10}{24,15}$ & $\frac{1,04}{29,85}$ & $\frac{10,04}{21,67}$ & $\frac{10,00}{22,41}$ \\
\hline $37,8-38$ & 42,68 & 37,29 & 40,78 & 18,89 & 63,44 & 53,66 & 63,80 & 51,68 & 22,64 & 20,05 & 22,59 & 18,14 & 32,84 & 35,58 & 28,04 & 26,21 \\
\hline $38-38,2$ & 22,55 & 9,37 & 4,09 & 0,05 & 18,49 & 14,93 & 11,44 & 7,16 & 43,11 & 42,22 & 38,50 & 27,41 & 26,31 & 14,52 & 17,65 & 9,85 \\
\hline \begin{tabular}{|l}
$0-2,2-38,4$ \\
88,
\end{tabular} & 0,23 & 0,27 & 0,06 & 0,07 & 0,13 & 3,57 & 0,41 & 4,76 & 19,05 & $\frac{7 L, \angle 2}{16,83}$ & 9,69 & 9 & 2,98 & 5,58 & 1.81 & 3,25 \\
\hline
\end{tabular}

Table 2: mean percentage of particles per year for different range of salinity

\begin{tabular}{|c|c|c|c|c|c|c|c|c|c|c|c|c|c|c|}
\hline & \multicolumn{2}{|c|}{ 15-mai } & \multicolumn{2}{|c|}{ 22-mai } & \multicolumn{2}{|c|}{ 29-mai } & \multicolumn{2}{|c|}{ 5-juin } & \multicolumn{2}{|c|}{ 12-juin } & \multicolumn{2}{|c|}{ 19-juin } & \multicolumn{2}{|c|}{ 26-juin } \\
\hline & PT & DVM & PT & DVM & PT & DVM & PT & DVM & PT & DVM & PT & DVM & PT & DVM \\
\hline $36,8-37$ & 0,68 & 0,66 & 0,75 & 2,59 & 1,55 & 2,62 & 1,09 & 2,73 & 0,81 & 0,60 & 0,98 & 0,40 & 0,25 & 0,52 \\
\hline $37-37,2$ & 2,78 & 5,19 & 1,98 & 5,08 & 2,49 & 6,17 & 2,63 & 4,83 & 1,45 & 1,64 & 1,42 & 1,27 & 0,88 & 1,72 \\
\hline $37,2-37,4$ & 9,39 & 13,81 & 7,08 & 13,35 & 4,69 & 9,27 & 5,14 & 8,88 & 3,74 & 5,53 & 2,59 & 5,28 & 3,65 & 3,76 \\
\hline $37,4-37,6$ & 20,38 & 24,25 & 15,91 & 23,89 & 12,72 & 20,70 & 9,10 & 20,00 & 9,58 & 14,98 & 7,43 & 13,81 & 5,22 & 6,42 \\
\hline $37,6-37,8$ & 34,56 & 37,97 & 36,58 & 32,65 & 34,35 & 34,93 & 26,81 & 27,22 & 29,26 & 35,69 & 28,30 & 34,73 & 25,15 & 29,47 \\
\hline $37,8-38$ & 23,30 & 12,53 & 27,08 & 16,24 & 30,00 & 16,80 & 36,96 & 28,33 & 40,52 & 30,49 & 44,30 & 35,89 & 50,46 & 43,38 \\
\hline $38-38,2$ & 6,50 & 1,94 & 7,96 & 1,21 & 8,85 & 2,70 & 12,97 & 4,02 & 10,55 & 6,95 & 12,45 & 6,59 & 12,78 & 11,58 \\
\hline
\end{tabular}

\begin{tabular}{|c|c|c|c|c|c|c|c|c|c|c|c|c|c|c|}
\hline & \multicolumn{2}{|c|}{ 3-juil } & \multicolumn{2}{|c|}{ 10-juil } & \multicolumn{2}{|c|}{ 17-juil } & \multicolumn{2}{|c|}{ 24-juil } & \multicolumn{2}{|c|}{ 31-juil } & \multicolumn{2}{|c|}{ 7-août } & \multicolumn{2}{|c|}{ 14-août } \\
\hline & PT & DVM & PT & DVM & PT & DVM & PT & DVM & PT & DVM & PT & DVM & PT & DVM \\
\hline $36,8-37$ & 0,31 & 0,31 & 0,22 & 0,45 & 0,21 & 0,09 & 0,26 & 0,12 & 0,29 & 0,24 & 0,14 & 0,28 & 0,50 & 0,88 \\
\hline $37-37,2$ & 0,51 & 0,55 & 0,39 & 0,68 & 0,34 & 0,42 & 0,46 & 0,22 & 0,56 & 0,42 & 0,25 & 0,39 & 0,66 & 1,74 \\
\hline $37,2-37,4$ & 1,49 & 1,46 & 0,79 & 1,46 & 0,71 & 0,87 & 1,33 & 0,63 & 1,34 & 1,04 & 0,40 & 1,00 & 0,92 & 2,38 \\
\hline $37,4-37,6$ & 5,72 & 9,24 & 2,47 & 3,35 & 1,39 & 2,26 & 2,70 & 2,17 & 3,01 & 2,69 & 1,61 & 3,92 & 1,97 & 4,06 \\
\hline $37,6-37,8$ & 18,86 & 20,46 & 14,50 & 19,34 & 6,03 & 10,68 & 6,31 & 10,07 & 9,69 & 15,68 & 9,17 & 14,43 & 8,64 & 14,99 \\
\hline $37,8-38$ & 51,56 & 44,18 & 54,64 & 44,79 & 56,71 & 59,59 & 46,25 & 43,66 & 41,42 & 44,96 & 37,55 & 32,27 & 35,42 & 24,34 \\
\hline $38-38,2$ & 19,08 & 16,50 & 23,38 & 19,20 & 29,84 & 20,41 & 36,33 & 34,65 & 37,18 & 24,37 & 43,24 & 37,16 & 42,82 & 36,82 \\
\hline
\end{tabular}

Table 3: mean percentage of particles per spawning date for different range of salinity 